\title{
Evaluation of Rainwater Utilization for Miscellaneous Water Demands in Different Types of Buildings Using Geographic Information System
}

\author{
Jinyoung Kim ${ }^{1}$, Kyoungjin $\mathrm{An}^{2 \dagger}$, Hiroaki Furumai ${ }^{3}$ \\ ${ }^{1}$ Information Analysis \& Assessment Center, National Disaster Management Institute, Ministry of Public Administration and Security, \\ Seoul 121-719, Korea \\ ${ }^{2}$ Department of Urban Engineering, The University of Tokyo, Tokyo 113-8656, Japan \\ ${ }^{3}$ Research Center for Water Environment Technology, The University of Tokyo, Tokyo 113-8656, Japan
}

\begin{abstract}
This study is an attempt to quantify rainwater utilization and miscellaneous water demand in Tokyo's 23 special wards, the core of the urban area in Tokyo, Japan, in order to elucidate the potential of further rainwater utilization. The rainwater utilization for miscellaneous appropriate water demands, including toilet flushing, air conditioning, and garden irrigation, were calculated for six different types of building: residential house, office, department store, supermarket, restaurant, and accommodation. Miscellaneous water demands in these different types of building were expressed in terms of equivalent rainfall of 767, 1,133, 3,318, 1,887, 16,574, and 2,227 (mm/yr), respectively, compared with 1,528 mm of Tokyo's average annual precipitation. Building types, numbers and its height were considered in this study area using geographic information system data to quantify miscellaneous water demands and the amount of rainwater utilization in each ward. Area precipitation-demand ratio was used to measure rainwater utilization potential for miscellaneous water demands. Office and commercial areas, such as Chiyoda ward, showed rainwater utilization potentials of $<0.3$, which was relatively low compared to those wards where many residential houses are located. This is attributed to the relatively high miscellaneous water demand. In light of rainwater utilization based on building level, the introduction of rainwater storage mechanisms with a storage depth of $50 \mathrm{~mm}$ for six different types of buildings was considered, and calculated as rainfall of 573, 679, 819, 766, 930, and 787 (mm), respectively. Total rainwater utilization using such storage facilities in each building from 23 wards resulted in the retention of 102,760,000 $\mathrm{m}^{3}$ of water for use in miscellaneous applications annually, and this volume corresponded to $26.3 \%$ of annual miscellaneous water demand.
\end{abstract}

Keywords: Miscellaneous water demand, Rainwater storage, Rainwater utilization potential, Type of building

\section{Introduction}

Water demand is concentrated in urban areas due to higher population densities, as well as the diversity of industries and facilities which require water supplies. Given future climate trends, which are expected to result in more frequent and severe droughts, it will be necessary to retain further rainwater resources as part of a sound hydrological cycle [1]. Much dam construction and water conveyance projects have been carried out for obtaining water resources to support urban activities, but to the reception for such water resource development projects had declined, due to environmental concerns, land usage priorities, and public levels of acceptance. Rainwater harvesting, on the other hand, is an effective way of satisfying our water demands with minimum impact on groundwater levels, since it reduces rainwater runoff. Additionally, the use of harvested rainwater contributes to reducing the amount of water taken from rivers and other natural water sources. Because of these benefits, as of the end of 2008 fiscal year there were around 3,400 facilities throughout Japan making use of rainwater and reclaimed water [2]. The average rainfall of Tokyo is $1,405 \mathrm{~mm} / \mathrm{yr}$, equivalent to the average daily amount of tap water supply; but half of this rainwater runs off directly into rivers and to the ocean [3]. It would be wise to utilize this rainwater, along with tap water, as water for domestic use, for use in urban activities, and for a variety of other water needs for cities [4].

In assessing the potential for using rainwater as a water resource in urban areas, in addition to the water balance analysis of water demand versus internal renewable water resources, which is widely used in assessing water scarcity due to climate (c) This is an Open Access article distributed under the terms of the Creative Commons Attribution Non-Commercial License (http://creativecommons. org/licenses/by-nc/3.0/) which permits unrestricted non-commercial use, distribution, and reproduction in any medium, provided the original work is properly cited.
Received July 25, 2012 Accepted April 24, 2013

${ }^{\dagger}$ Corresponding Author

E-mail: kjan0920@gmail.com

Tel: +81-3-5841-6250 Fax: +81-3-5841-6249 
change [5, 6], it is important to carry out a multifaceted evaluation of factors such as the amount of water used in urban activities, the quality of rainwater, and local characteristics, taking into account spatial distribution. Watanabe et al. [7] developed water balance diagrams of 23 major cities in Japan, and conducted research on water use stress, taking into account such quantitative factors as a city's water self-sustainability and utilization ratio of its own internal water resources. Murakami and Furumai [8] discussed the possibility of using rainwater for different purposes according to the quality level of the rainwater. Another study examined the feasibility of installing rainwater storage tanks in existing buildings in low-lying parts of Tokyo's special wards, based on geographic information system (GIS) data and field surveys, and estimated the benefits of rainwater harvesting [3].

In this study, based on the use of rainwater for miscellaneous purposes and focusing on the water demands of different types of buildings: 1) we made use of GIS data and various statistical data to estimate water demand in the Tokyo wards, taking into account miscellaneous water usage patterns per building type; 2) we proposed a method for relatively and quantitatively determining rainwater utilization potential based on the amount of available rainwater resources and miscellaneous water demands per building type. This was then applied to the 23 Tokyo wards; and 3) assuming miscellaneous water use to be augmented by rainwater harvesting based on the roof area of individual buildings, we evaluated the benefits of such usage and considered the effectiveness of rainwater utilization from the standpoints of reducing the water supply burden in large cities and stabilizing water resources.

\section{Materials and Methods}

\subsection{Ratio of Miscellaneous Water Use to Total Water Us- age Amount per Building Type}

Table 1 summarizes the ratio of miscellaneous water use to total water usage amount per building type in Tokyo. The miscellaneous water uses are of three kinds, for toilet flushing (TF), air conditioning (AC), and garden watering (GW), not requiring

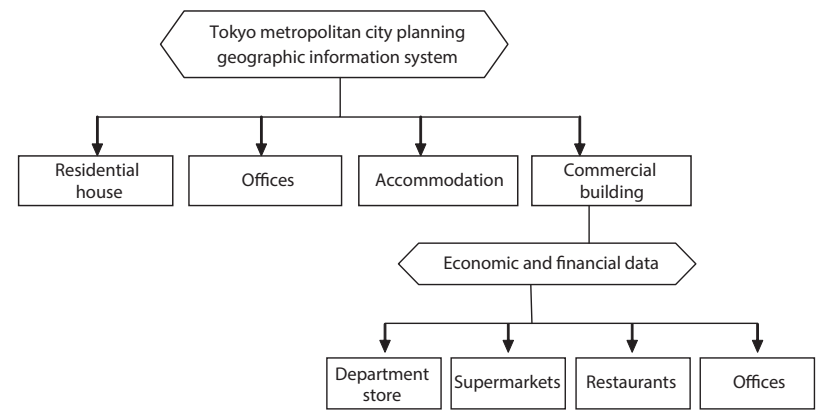

Fig. 1. Classification of building types and data used.

water of potable quality. While the table divides restaurants into three types, water demand was calculated based on the average unit demand across these three types to avoid complicating the classification of building types. Tokyo's the average miscellaneous water demand for restaurants, department stores, accommodations, supermarkets, office buildings, and residential houses are $51.9,9.8,9.4,5.6,4.7$, and 2.1 (L/ $\mathrm{m}^{2} /$ day), respectively [9]. The miscellaneous water demand unit for restaurants is notably higher than that of other building types.

\subsection{Classification of Building Types in the Tokyo Wards}

For classifying buildings based on their purposes for miscellaneous water use, we referred an electronic database on building status of the Tokyo Metropolitan City Planning Geographic Information System (2001), as shown in Fig. 1.

The data relates to the classification of buildings on residential land into 15 types, namely, government buildings, educational and cultural facilities, health and welfare facilities, utilities and waste disposal facilities, office buildings, dedicated commercial facilities, combined residential and commercial buildings, accommodations, sports facilities, detached houses, multi-family residences, dedicated factories, combined residences and factories, storage and transport facilities, and agriculture and fishery facilities, etc. For each building there are 20

Table 1. Water demand units by building type and percentage of water use

\begin{tabular}{|c|c|c|c|c|c|c|c|c|c|c|}
\hline \multirow{3}{*}{ Building type } & \multirow{3}{*}{$\begin{array}{c}\text { Unit } \\
\left(\mathrm{L} / \mathrm{m}^{2} / \text { day) }\right.\end{array}$} & \multicolumn{9}{|c|}{ Water usage $(\%)$} \\
\hline & & \multicolumn{4}{|c|}{ Miscellaneous use } & \multicolumn{5}{|c|}{ Non-miscellaneous use } \\
\hline & & TF & AC & GW & Sum & Hand wash & Bath & Laundry & Kitchen & Other \\
\hline Residential house & 10.0 & 21 & 0 & 0 & 21 & 8 & 21 & 24 & 26 & 0 \\
\hline Offices & 8.1 & 30 & 25 & 3 & 58 & 15 & 0 & 0 & 27 & 0 \\
\hline \multicolumn{11}{|c|}{ Commercial (sale of goods) } \\
\hline Department stores & 21.8 & 40 & 4 & 1 & 45 & 7 & 0 & 0 & 44 & 4 \\
\hline Supermarkets & 12.4 & 40 & 4 & 1 & 45 & 7 & 0 & 0 & 44 & 4 \\
\hline \multicolumn{11}{|c|}{ Commercial (restaurants) } \\
\hline Restaurants $^{\mathrm{a}}$ & 205 & 30 & 5 & 2 & 37 & 5 & 0 & 0 & 55 & 3 \\
\hline Restaurants $^{\mathrm{b}}$ & 130 & 28 & 5 & 2 & 35 & 5 & 0 & 0 & 57 & 3 \\
\hline Restaurants $^{c}$ & 110 & 25 & 5 & 2 & 32 & 5 & 0 & 0 & 60 & 3 \\
\hline Accommodation & 24.2 & 20 & 18 & 1 & 39 & 5 & 28 & 3 & 25 & 0 \\
\hline
\end{tabular}

TF: toilet flushing, AC: air conditioning, GW: garden watering.

${ }^{a}$ Chinese, French, Korean, etc. ${ }^{b}$ Family restaurants, night clubs, etc. ${ }^{c} J a p a n e s e$ (noodles, sushi), coffee shops, etc. 
layers of data, including number of floors, below-ground floors, structure, purpose, area, and location. The present study covers 13 types of buildings, omitting agriculture and fishery facilities as well as factories, which have water supply systems different from ordinary systems. For each of these 13 types of buildings we compiled statistical data on the roof area, number of floors, and number of buildings.

Since, the Tokyo Metropolitan City Planning Geographic Information System does not include department stores, supermarkets, or restaurants in its building classification; we investigated the numbers of these building types in the Tokyo wards using the statistics from economic and financial data by the Ministry of Internal Affairs and Communications [10]. Since department stores have the same purpose throughout the building, we simply used the number of buildings as it is. Supermarkets and restaurants, on the other hand, may combine different kinds of services in the same building, so we adopted a method of distributing the number of supermarkets and restaurants among dedicated commercial use and combined commercial and residential use buildings.

GIS data of Zmap-TOWN II (ZENRIN Co., Ltd., Fukuoka, Japan) was used to identify buildings in the study area and to classify building types based on their usage. This map contains detailed information on individual buildings in the attribute table of the vector layer, such as building and owner names, number of stories, and business type. The data reflects the situation in 2000. Each building type was characterized using usage/business type information which was contained in the attribute table of the GIS map.

\subsection{Evaluating Rainwater Utilization Potential for Miscel- laneous Water Use}

This study defined rainwater utilization potential as the ratio of available rainwater to the amount of miscellaneous water demand. While there may be constraints on rainfall use such as economic or installation feasibility, we looked at utilization potential assuming the maximum possible usage of rainfall over a year.

As for the rainfall data, we used AMeDAS (Japan weather satellite) hourly precipitation data from Otemachi, Tokyo. The Japan Meteorological Agency calculates average annual rainfall using observations for year 1981 to 2010 , so we used the rainfall data for that period to find the average annual rainfall amount in Tokyo. Moreover, we determined dry years and wet years with the minimum and maximum rainfall in the past ten years (2001-2010), in line with the concept of standard drought water discharge assumed to occur around once every ten years.

Based on the water demand for each building type, we calculated annual water demand, taking into account the following constraints on water use.

1) Use of air conditioning for a three-month period between July and September.

2) Garden watering for a nine-month period between March and November, but not on rainy days.

In order to estimate demand for miscellaneous water relative to the amount of rainfall, we used this demand in units of $\mathrm{mm} / \mathrm{yr}$ as equivalent rainfall per unit building area.

\subsection{Analyzing the Benefits of Rainfall Harvesting and Use}

We calculated how much rainwater could be collected from

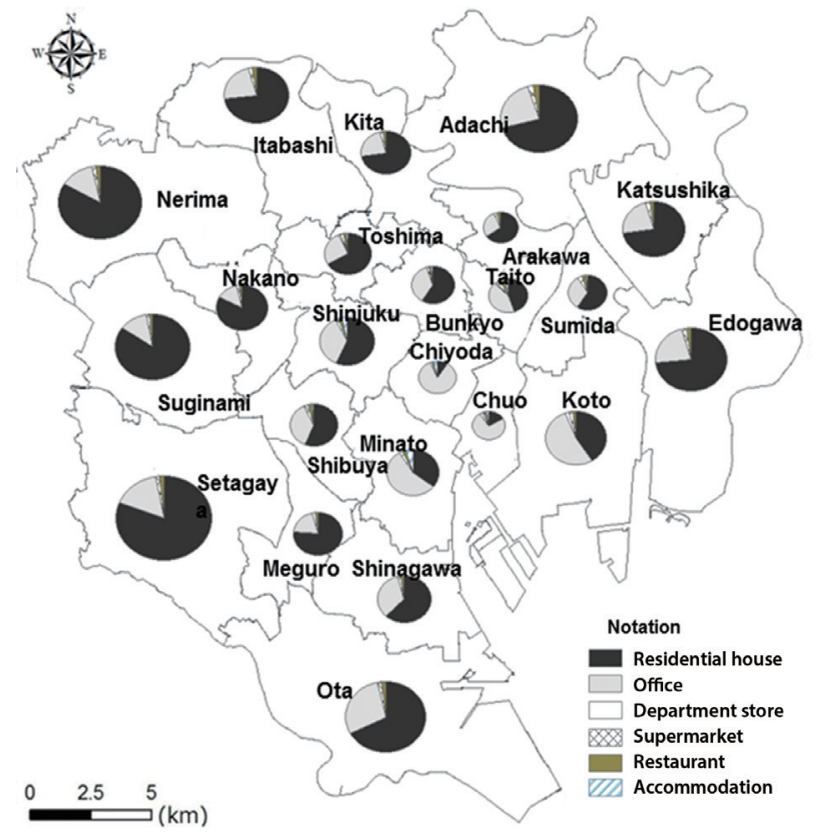

Fig. 2. Building type ratios in Tokyo 23 wards.

building roofs and utilized as miscellaneous water use. The rainwater harvesting facilities were assumed to be large enough to hold up to $50 \mathrm{~mm}$ of rainwater. Since the Act on Maintenance of Sanitation in Buildings sets a water quality turbidity standard of 2 degrees as a water quality control standard, in this analysis we calculated the amount of collected rainwater assuming a limit of $2 \mathrm{mg} / \mathrm{L}$ or below for suspended solids (SS) in rainwater flowing into the storage facilities. For calculating SS concentration in rainwater, we used the model of Hijioka and Furumai [11] and parameters such as sediment amount and runoff were adopted from this model.

\section{Results and Discussion}

\subsection{Building Type Classifications}

Based on the classification of building types in the Tokyo wards, the ratio of residential houses, offices, department stores, supermarkets, restaurants and accommodation and their distribution in each ward are as shown in Fig. 2 using GIS.

The most common uses of buildings are for residential house and office purposes; these two uses combined make up $94 \%$ of the total building area within the Tokyo wards. Of the 23 wards, Suginami, Nerima, and Nakano have the highest ratio of residential houses, accounting for more than $80 \%$ of the total building area; and buildings for office use are the smallest in area at $13 \%$, $14 \%$, and $14 \%$, respectively. Chiyoda and Chuo wards have the highest ratio of office buildings at more than $82 \%$ and $72 \%$ of the total building area, with housing taking up the smallest area at $10 \%$ and $17 \%$, respectively. In the overall Tokyo ward area, office buildings are heavily concentrated in the area along Tokyo Bay, which includes Chiyoda ward, while residential houses are concentrated in the parts surrounding this area. 


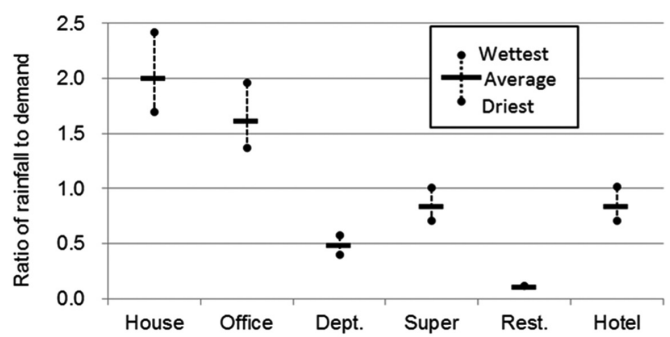

Fig. 3. Ratio of rainfall to miscellaneous water demand per building type (during the analysis period, the rainfall during the driest year 2002 was $1,295 \mathrm{~mm}$ and that during the wettest year 2008 was 1,858 $\mathrm{mm})$. Dept.: department store, Super: supermarket, Rest.: restaurant.

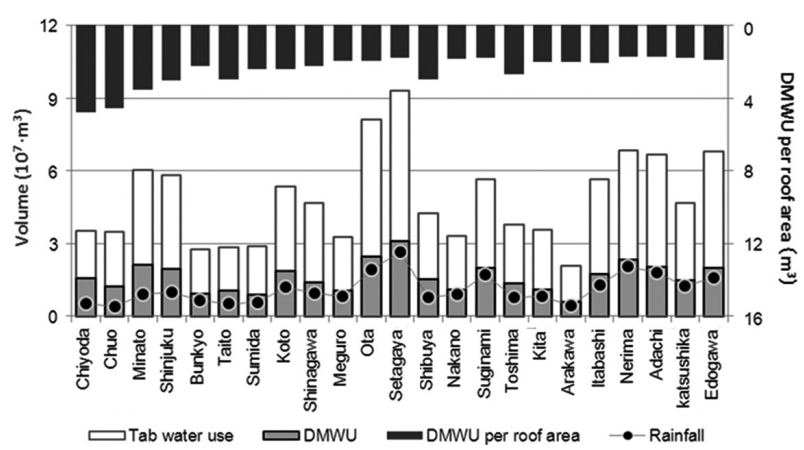

Fig. 4. Miscellaneous water demand and rainfall in the Tokyo wards. DMWU: demand for miscellaneous water use.

\subsection{Rainwater Utilization Potential per Building Type}

Average annual rainfall of Tokyo and miscellaneous water demand per building type are summarized in Table 2. Compared to average annual rainfall over the past 30 years of 1,594 mm, annual miscellaneous water demand was $767,1,133,3,318,1,887$, 16,574 , and 2,227 mm, respectively, for residential houses, offices, department stores, supermarkets, restaurants, and accommodation. Taking the miscellaneous water demand in residential houses as base, the demand for offices, department stores, supermarkets, restaurants, and accommodation facilities is 1.5, $4.3,2.5,21.6$, and 2.9 times this amount, respectively.

In addition, Fig. 3 shows the ratio of rainfall to miscellaneous water demand for each building type.

We also see that the ratio of average annual rainfall to miscellaneous water demand for each building type is 2.0, 1.6, 0.5, $0.8,0.1$, and 0.8 times, respectively. While there is variation between dry and wet years, in the case of the residential and office buildings, making up the majority of buildings in Tokyo, the amount of rainfall exceeds miscellaneous water demand. This indicates that the potential for utilizing rainwater in meeting the demand is higher for residential and office buildings than for other building types. For restaurants, on the other hand, among the six building types, it seems to be quite difficult to meet their demand by rainwater utilization alone.

\subsection{Rainwater Utilization Potential in Each Tokyo Ward}

We calculated miscellaneous water demand, taking into account the numbers of buildings and floors, etc., in each ward. Fig. 4 shows the amount of miscellaneous water demand in each of the 23 wards along with the tap water supply amount in year 2006 data, rainfall and miscellaneous water demand per roof area.

Both tap water supply and miscellaneous water demand are highest in Setagaya and Ota wards. In miscellaneous water demand, Minato ward is in third place following these two wards. The reasons for the high demand in these wards are the large area of residential housing in the case of Setagaya and Ota wards, and for Minato ward, the high ratio of office buildings and higher than average number of floors than in other parts of Tokyo. In terms of miscellaneous water demand per roof area, the top three wards are Chiyoda, Chuo, and Minato wards, reflecting the concentration of office buildings and tall buildings in the central business area of Tokyo. The results also show that in the Tokyo wards, demand for miscellaneous water ranges from 30\% (Arakawa ward) to $52 \%$ (Chiyoda ward) of existing tap water usage.

Fig. 5 shows the area precipitation-demand ratio (APDR), indicating the rainwater utilization potential compared to miscellaneous water demand, for the Tokyo wards. Using the data for miscellaneous water demand by building type as equivalent rainfall of Table 2, we define the APDR using the following equation.

$$
A P D R=\sum_{i=1}^{k}\left(\frac{p}{D_{i}} \times F_{i} \times \frac{n_{i}}{N}\right)
$$

Here, $\mathrm{i}$ is the building purpose type identification factor, $\mathrm{k}$ is the number of building types $(k=6), D$ is miscellaneous water demand $(\mathrm{mm}), \mathrm{P}$ is annual precipitation, $\mathrm{F}$ is average number of building floors, $\mathrm{n}$ is number of buildings of each type, and $\mathrm{N}$ is the total number of buildings covered. The feasibility of rainwater collection facility installation is not included in the equation.

Rainwater utilization potential differs between the central areas around Chiyoda ward, which contain high concentrations of office and commercial buildings, and the surrounding areas, which contain many residential buildings, while the areas inbetween are well represented as with a mixture of both kinds of buildings. The six wards-Nerima, Adachi, Suginami, Setagaya, Nakano, and Katsushika — have high rainwater utilization potential of APDR 0.8 or above. Chiyoda and Chuo wards, on the other hand, have low rainwater utilization potential of 0.3 or below. These results indicate the need for different rainfall utilization plans in residential areas and in office and commercial areas. In the residential areas, for example, it should be possible to meet a significant part of miscellaneous water demands with roof rain-

Table 2. Average rainfall of Tokyo in the past 20 years and miscellaneous water demand by building type as equivalent rainfall

\begin{tabular}{ccccccc}
\hline \multirow{2}{*}{$\begin{array}{c}\text { Average rainfall } \\
(\mathbf{m m} / \mathbf{y r})\end{array}$} & \multicolumn{5}{c}{ Miscellaneous water demand $(\mathrm{mm} / \mathrm{yr})$} \\
\cline { 2 - 7 } & Residential house & Office & Department store & Supermarket & Restaurant & Accommodation \\
\hline 1,594 & 767 & 1,133 & 3,318 & 1,887 & 16,574 & 2,227 \\
\hline
\end{tabular}




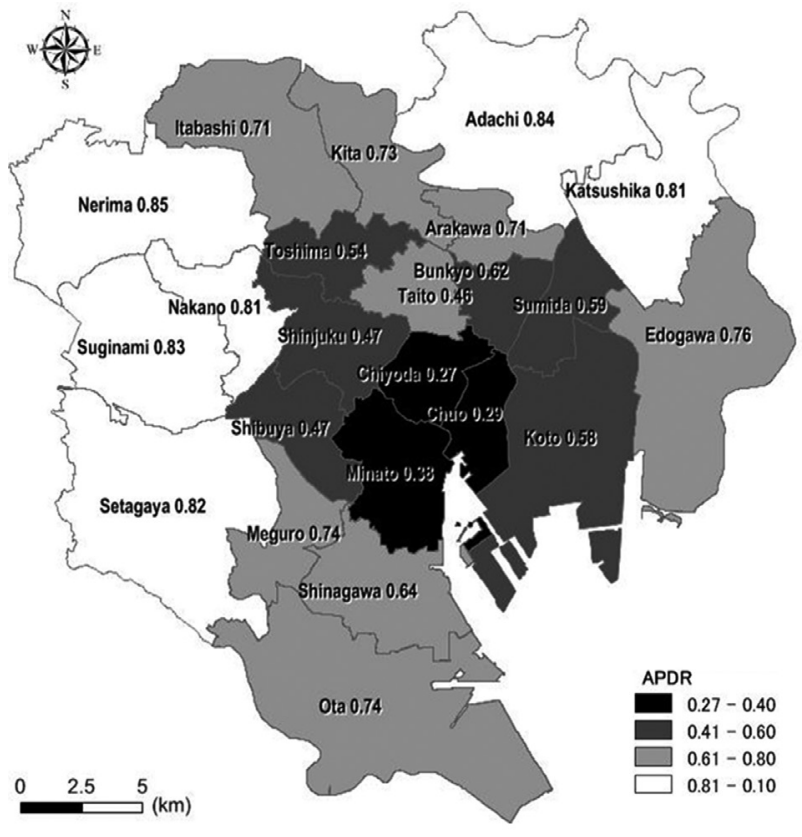

Fig. 5. Area precipitation-demand ratio (APDR) in Tokyo wards.

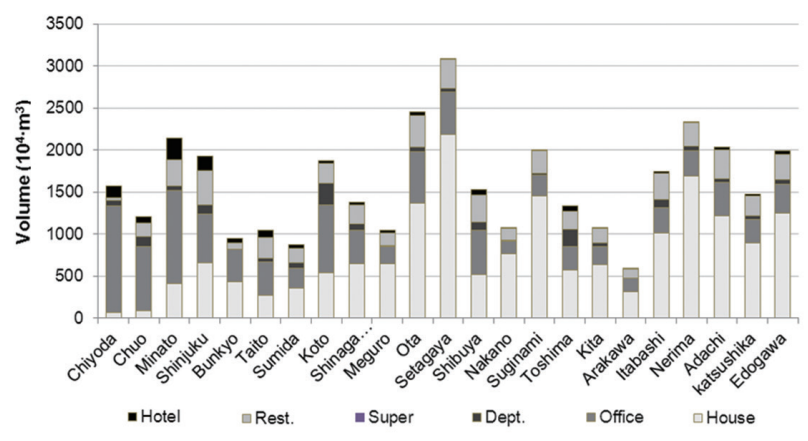

Fig. 6. Amounts of miscellaneous water demand by building type and rainwater utilization. Dept.: department store, Super: supermarket, Rest.: restaurant.

water, whereas in office and commercial areas roof water collection alone is not enough, making it necessary to install largescale rainwater harvesting facilities on relatively large public areas such as parks, in order to make extensive use of reclaimed water.

\subsection{Benefits of Rainwater Harvesting and Using Building Roof}

To evaluate the benefits of introducing rainwater harvesting facilities, we considered a scenario in which facilities for collecting up to $50 \mathrm{~mm}$ of rainfall are introduced for all buildings in each ward. The amount of rainfall that can be utilized by collecting and using building roof rainfall was calculated to be 573,679 , 819, 766, 930, and 787 ( $\mathrm{mm}$, equivalent rainfall) for residential houses, offices, department stores, supermarkets, restaurants, and accommodation, respectively.

Based on the ratios of building types in each ward, the amounts of miscellaneous water demand for each building type and rainwater available for those uses are shown in Fig. 6. Harvesting rainwater from building roofs throughout Tokyo wards, based on the aforementioned assumptions, would recover a maximum of $102.76 \times 10^{6} \mathrm{~m}^{3}$ of rainwater for miscellaneous water uses. This amount is equivalent to $9.2 \%$ of the annual tap water supply and $26.2 \%$ of the annual miscellaneous water demand in the Tokyo wards. Of the 23 wards, rainwater utilization would be greatest in Setagaya ward $\left(10.2 \times 10^{6} \mathrm{~m}^{3}\right)$, Nerima ward $(7.9 \times$ $\left.10^{6} \mathrm{~m}^{3}\right)$, and Ota ward $\left(7.6 \times 10^{6} \mathrm{~m}^{3}\right)$, equivalent to $47 \%, 48 \%$, and $57 \%$ of their respective residential house miscellaneous water demand.

\section{Conclusions}

In the Tokyo wards, buildings cover $27 \%$ of the total administrative area, and therefore can be very effective in harvesting and storing rainwater. One of the good examples of large scale rainwater harvesting facility is Ryogoku Kokugikan (Sumo wrestling arena) in Tokyo. Another symbolic example is a rainwater tank at Tokyo Dome, which is not only utilized for rainwater harvesting, but also for flood control and as an emergency water supply. In managing water resources properly geared to the complex water use structures in urban areas, it is important to use buildings as basic units of water usages while taking into account the different water use patterns in different building types and determining the water use balance. In this study, we considered the miscellaneous water demand of each building type in the Tokyo wards as well as the distribution features in each ward and then clarified the difference in rainwater utilization potential and benefits between commercial and residential areas.

The water resource obtained by rainwater harvesting facilities should be useful in reducing the water supply burden and enabling urban areas to obtain stable water resources. In business centers such as Chiyoda ward with concentrated water demands, it will be more feasible to consider not only using rainwater but also combining this with other alternative water resources such as reclaimed water.

\section{References}

1. Ministry of Environment of Japan. Wise adaptation to climate change: report by the Committee on Climate Change Impacts and Adaptation Research. Tokyo: Ministry of Environment; 2008.

2. Water Resources Department, Ministry of Land, Infrastructure, Transport and Tourism. A platform for rainwater and reclaimed water use [Internet]. Tokyo: Ministry of Land, Infrastructure, Transport and Tourism; c2013 [cited 2013 May 1]. Available from: http://www.mlit.go.jp/tochimizushigen/ mizsei/g_resources/fukyu/fukyujyokyo.html.

3. Wanami K, Shimazu T. Study on rain water use and outflow control (1). In: Annual report of the Tokyo Metropolitan Research Institute for Environmental Protection. Tokyo: Tokyo Metropolitan Research Institute for Environmental Protection; 2004. p.110-116.

4. Furumai H. Towards the wise management along with urban rainwater. J. Water Waste 2010;52:285-287. 
5. United Nations Educational, Scientific and Cultural Organization; United Nations World Water Assessment Programme. Water: a shared responsibility. Paris: United Nations Educational, Scientific and Cultural Organization; 2006.

6. Zhou YC, Shao WY, Zhang TQ. Analysis of a rainwater harvesting system for domestic water supply in Zhoushan, China. J. Zhejiang Univ. Sci. Appl. Phys. Eng. 2010;11:342-348.

7. Watanabe H, Murakami M, Komura T, Moroizumi T, Furumai $\mathrm{H}$. Evaluation of water balance and water use stress in principal cities in Japan. J. Water Waste 2009;51:137-148.

8. Murakami M, Furumai H. Water quality in urban rainfall and runoff and new trends for their use. J. Water Waste 2010;52:288-296.
9. Society of Heating, Air-Conditioning and Sanitary Engineers of Japan. Design and operation of a rainwater use system. Tokyo: Society of Heating, Air-Conditioning and Sanitary Engineers of Japan; 1997.

10. Bureau of General Affairs, Tokyo Metropolitan Government. Report on Establishment and Enterprise Census results for Tokyo [Internet]. Tokyo: Bureau of General Affairs, Tokyo Metropolitan Government; c2011 [cited 2013 May 1]. Available from: http://www.toukei.metro.tokyo.jp/jigyou/jg-index.htm.

11. Hijioka Y, Furumai H. Modified washoff models of roof and road for urban non-point pollution analysis. Proc. Japan Soc. Civ. Eng. 2001;(685):123-134. 